\title{
The need for research evidence to meet health workforce challenges in the Eastern Mediterranean Region
}

Fethiye Gulin Gedik, ${ }^{1}$ James Buchan, ${ }^{2}$ Zafar Mirza, ${ }^{3}$ Arash Rashidian, ${ }^{4}$ Sameen Siddiqi ${ }^{5}$ and Gilles Dussault ${ }^{2}$

${ }^{1}$ Coordinator, Health Workforce Development, World Health Organization Regional Office for the Eastern Mediterranean, Cairo, Egypt. ${ }^{2}$ Global Health and Tropical Medicine, Instituto de Higiene e Medecina Tropical, Universidade Nova de Lisboa, Lisbon, Portugal. ${ }^{3}$ Director, Health System Development, World Health Organization Regional Office for the Eastern Mediterranean, Cairo, Egypt. ${ }^{4}$ Director, Information, Evidence and Research, World Health Organization Regional Office for the Eastern Mediterranean, Cairo, Egypt. ${ }^{5}$ Chair, Community Health Sciences, Aga Khan University, Karachi, Pakistan.

Citation: FG Gedik; Buchan J; Mirza Z; Rashidian A; Siddiqi S; Dussault G. The need for research evidence to meet health workforce challenges in the Eastern Mediterranean Region. East Mediterr Health J. 2018.24.9.811-812. https://doi.org/10.26719/2018.24.9.811

Copyright (c) World Health Organization (WHO) 2018. Some rights reserved. This work is available under the CC BY-NC-SA 3.0 IGO license (https:// creativecommons.org/licenses/by-nc-sa/3.o/igo).

The countries of the World Health Organization (WHO) Eastern Mediterranean Region signed the UHC2030 Global Compact collectively at the Ministerial Meeting on the Road to Universal Health Coverage (UHC) in Salalah, Oman, 3-5 September, 2018 (1). In the Compact, they expressed their commitment to working together with renewed urgency to accelerate progress towards UHC, through building and expanding equitable, resilient and sustainable health systems. Universal Health Coverage is the overarching target for achieving the Sustainable Development Goals (SDGs) especially the Goal 3 of Health and Wellbeing, and is the key objective of WHO's general programme of work for the next five years (2).

Health workforce has a fundamental role in enabling progress towards UHC. There is a growing recognition that the demand for health services generated by population growth and ageing is placing an increased emphasis on how countries train, recruit, deploy, retain and manage their health workforce. This has led to an unprecedented and highly welcome focus on health workforce policy, planning, production and their deployment and continued development. This focus plays out at all levels from global to local and recognizes the interconnectedness between the different levels, and the need to ensure aligned policy responses to health workforce challenges.

At a global level, the necessary and appropriate policy responses are well described in the WHO Global Strategy on Human Resources for Health: Workforce 2030 adopted by the Sixty-ninth World Health Assembly in 2016 (3). This strategy has lent itself to the development of regionally specific frameworks, including in the Eastern Mediterranean Region (EMR) (4).

In 2006, the World Health Report drew attention to a global shortage of health workers and identified 57 countries out of 192 that reported having less than 23 physicians, nurses and midwives in 10000 population. This was a threshold below which $80 \%$ of basic maternal and child health services could not be provided. Of these 57 countries, seven were EMR Member States (5); more than a decade later, the health workforce situation is still critical in these seven countries. When considering the more ambitious targets of SDGs and increased threshold levels, studies and projections supporting the recent Global Health Workforce Strategy have estimated a shortage of 17 million health workers globally, of which almost 2.6 million are doctors, 9 million are nurses and midwives, and the remainder represent all other cadres (2). Current trends of production and employment will not have a sufficient impact on reducing the needs-based shortage of healthcare workers, which is projected to remain at more than 14 million globally by 2030 (2).

In the EMR there are also geographical, skill-mix and gender imbalances in the health workforce. Health workforce mobility is increasing among countries within as well as out of the Region, with some countries remaining highly reliant on expatriate staff, while others are depleted of their health professionals due to emigration. Competition from the private sector and dual practice also lead to shortages and high workloads in the public sector in many EMR countries. Despite the magnitude of dual practice among physicians in the Region, empirical studies are limited (6), and potential solutions are difficult to design and implement (7). There are also concerns in relation to the quality and productivity of health workers (3). Almost half of EMR countries are affected by emergencies and conflict, which exacerbate shortages, lack of security, mobility and availability of health workers; $86 \%$ of health workers killed or injured globally during 2014-2015 were from the Eastern Mediterranean Region (8).

In response to these challenges, the WHO Regional Office for the Eastern Mediterranean developed a Framework for Action for Health Workforce Development, endorsed by the Regional Committee in 2017, to accelerate action for addressing health workforce challenges towards achieving UHC and the SDGs (3). The Framework for Action calls for Member States to develop comprehensive health workforce strategic plans based on a valid understanding of health labour market dynamics, mobilize investment for health workforce development, strengthen governance and regulatory capacities, and improve health workforce information and evidence. The Framework proposes strategies to ensure the availability 
of a fit-for-purpose, motivated and responsive health workforce accessible to all people of the Region (4). The Framework insists that the first step is to utilize more effectively the current workforce through continuous development and retraining, changes in skill-mix and scope of practice, and redeployment.

This special issue of the Eastern Mediterranean Health Journal presents in three sections examples of original analysis and the application of analytical tools and applied research to inform policy and enhance implementation. This is also in line with a developing regional strategy for enhancing production of regionally relevant research evidence and improving evidence informed decision-making (9-11). The first section presents examples of research to improve our understanding of aspects of health workforce behaviour, choice, allocation and impact. These research articles report on the extent of dual practice, workforce planning and the use of a workload estimation tools to support primary care workforce planning, the pattern of nursing research activity in the Region, public health education, and factors related to location choice and to retention of medical doctors. These papers clearly show that there is a broad range of appropriate research methods which can be utilised to inform and support improvements in health workforce policy and planning, locally and nationally.

The second section presents short reports on health professional capacity building, including interprofessional education, competency based curriculum development, field epidemiology training, an assessment of pharmacy workforce development opportunities, the development of a national competency-based curriculum for technical nurses, and capacity building in "health diplomacy".

The final section presents three reviews on addressing health workforce shortages and maldistribution, and transformation of nursing education. Overall, this thematic issue provides additional analysis and evidence relevant to the Region. It can assist policy-makers and inspire other researchers and policy analysts to contribute further to improving and extending our knowledge of how best to address health workforce challenges. Meanwhile, the WHO Regional Office for the Eastern Mediterranean is committed to helping Member States scale up their health workforce capabilities in the quest for accelerated progress towards Universal Health Coverage.

\section{References}

1. Ministerial meeting paves the way for universal health coverage in the Region. Cairo: WHO Regional Office for the Eastern Mediterranean; 2018 (http://www.emro.who.int/media/news/ministerial-meeting-aims-to-pave-the-way-towards-universal-health-coverage-in-the-eastern-mediterranean-region.html).

2. Mahjour J, Mirza Z, Rashidian A, Atta H, Hajjeh R, Thieren M, et al. "Promote health, keep the world safe, serve the vulnerable" in the Eastern Mediterranean Region. East Mediterr Health J. 2018;24(4):323-324. https://doi.org/10.26719/2018.24.4.323 PMID: 30370917

3. Global Strategy on Human Resources for Health: Workforce 2030. Geneva: World Health Organization; 2016 (http://apps.who.int/ iris/bitstream/handle/10665/250368/9789241511131-eng.pdf;jsessionid=103C2503C99F32569Do6A02ACA88FAAE?sequence=1).

4. Framework for Action for Health Workforce Development in the Eastern Mediterranean Region 2017-2030. Cairo: World Health Organization Regional Office for the Eastern Mediterranean; 2018 (http://applications.emro.who.int/docs/EMROPub_2018_ EN_20314.pdf?ua=1).

5. Working Together for Health. The World Health Report. Geneva: World Health Organization; 2006 (http://www.who.int/ whr/2006/whro6_en.pdf).

6. Moghri J, Rashidian A, Arab M, Akbari Sari A. Implications of Dual Practice among Health Workers: A Systematic Review. Iran J Public Health. 2017; 46(2):153-164 PMID: 28451549

7. Bazyar M, Rashidian A, Jahanmehr N, Behzadi F, Moghri J, Doshmangir L. Prohibiting physicians' dual practice in Iran: Policy options for implementation. Int J Health Plann Manage. 2018. https://doi.org/10.1002/hpm.2524 PMID: 29683205

8. Report on attacks on healthcare in emergencies. Geneva: World Health Organization; 2016 (http://www.who.int/hac/techguidance/attacksreport.pdf).

9. Rashidian A, Mandil A, Mahjour J. Improving policy-making for health in the Eastern Mediterranean Region. East Mediterr Health J. 2018 Mar 5;23(12):793-794 PMID: 29528087

10. El-Jardali F, Mandil A, Jamal D, BouKarroum L, El-Feky S, Nour M, Al-Abbar M. Engagement of health research institutions in knowledge translation in the Eastern Mediterranean Region. East Mediterr Health J. 2018 Sep 6;24(7):672-679 PMID: 30215477

11. Mandil A, El-Jardali F, El-Feky S, Nour M, Al-Abbar M, BouKarram L. Health research institutional mapping: an Eastern Mediterranean Regional perspective. East Mediterr Health J. 2018 May 3;24(2):189-197. PMID: 29748948 